\title{
Abnormal small bowel permeability and duodenitis in recurrent abdominal pain
}

\author{
S B van der Meer, P P Forget, J W Arends
}

\begin{abstract}
Thirty nine children with recurrent abdominal pain aged between 5.5 and 12 years, underwent endoscopic duodenal biopsy to find out if there were any duodenal inflammatory changes, and if there was a relationship between duodenal inflammation and intestinal permeability to ${ }^{51} \mathrm{Cr}$-EDTA. Duodenal inflammation was graded by the duodenitis scale of Whitehead et al (grade $0,1,2$, and 3). In 13 out of 39 patients (33\%) definite signs of inflammation were found (grade 2 and 3 ). Intestinal permeability to ${ }^{51} \mathrm{Cr}$-EDTA in patients with duodenitis (grade 1, 2, and 3) was significantly higher $(4.42(1.73) \%)$ than in patients with normal (grade 0 ) duodenal biopsy appearances (3.3 (0.9)\%). A significant association was found between duodenal inflammation and abnormal intestinal permeability. Our results give further evidence that there is an intestinal origin of these patients' complaints.
\end{abstract}

About $10-15 \%$ of children of school age regularly complain of abdominal pain. ${ }^{12}$ In most cases no underlying cause can be found. In a large study done in 1958 Apley claimed to be able to find somatic causes, such as urinary tract infections and peptic ulcers, in only $10 \%$ of the patients. ${ }^{2}$ Since then various other possible causes have been suggested, including lactose intolerance, ${ }^{3}$ abnormal gastroduodenal motility, ${ }^{4}$ and even 'appendiceal colic'. 5 Much attention has been drawn by psychosocial conditions as a potential cause of the complaints. ${ }^{67}$ Case controlled studies, however, have not established a clear relationship between abdominal pain and psychosocial conditions. ${ }^{89}$

In a previous study we report abnormal intestinal permeability in children with recurrent abdominal pain, using orally administered ${ }^{51} \mathrm{Cr}$-EDTA as a marker. ${ }^{10}$ In $54 \%$ of our patients we found that the ${ }^{51} \mathrm{Cr}$-EDTA excretion was more than $3.5 \%$, considered to be the upper limit of the reference range in children. ${ }^{11}$ As the urinary excretion of ${ }^{51} \mathrm{Cr}$-EDTA has been shown to be abnormal in several conditions known to be associated with mucosal inflammation such as coeliac disease, ${ }^{11}$ Crohn's disease, ${ }^{12}$ and gastroenteritis, ${ }^{13}$ we suggested that intestinal inflammation may be present in our patients with recurrent abdominal pain. We had no histological evidence to support this hypothesis, however. The purpose of the present study therefore was to find out the incidence of intestinal inflammation in our patients with recurrent abdominal pain and to assess the value of ${ }^{51} \mathrm{Cr}$-EDTA permeability tests of intestinal inflammation. As the absorption of ${ }^{51} \mathrm{Cr}$-EDTA takes place predominantly in the small bowel, ${ }^{12}$ duodenal biopsies from 39 patients with recurrent abdominal pain were examined for the presence of inflammatory changes.

\section{Patients and methods}

During a prospective study 106 children with recurrent abdominal pain were investigated according to a standard protocol. Patients were diagnosed as having recurrent abdominal pain if they were aged between 5.5 and 12 years; had had recurrent abdominal pain for at least six months; had had attacks of pain varying in severity, duration, and frequency; and if their attacks were sometimes accompanied by paleness, nausea, and vomiting. These criteria are in accordance with those first laid down by Apley, ${ }^{12}$ except for the duration of the complaints, for which we felt that a six month period was more justifiable. All children referred to our outpatient clinics with recurrent abdominal pain and those admitted to the paediatric ward who met the inclusion criteria, were admitted to the study. All children were referred to us by their family doctors or by school doctors. Both groups of colleagues were informed about the study. All parents gave informed consent, in only two cases did the parents refuse to take part.

The protocol consisted of a standard physical examination; routine laboratory investigations of blood, faeces, and urine, and a standard ultrasound examination of the abdomen. Lactose tolerance was tested with an oral lactose load of $2 \mathrm{~g} / \mathrm{kg}$ body weight, with a maximum of $50 \mathrm{~g}$. Breath samples were analysed at 30 minute intervals for two hours, with a Lactoscreen (HoekLoos). Hydrogen content of breath samples was considered abnormal if it exceeded 20 ppm.

The ${ }^{51} \mathrm{Cr}$-EDTA permeability test was done as previously described. ${ }^{10}$ Briefly, after an overnight fast a dose of $100 \mu \mathrm{Cu}{ }^{51} \mathrm{Cr}$-EDTA was given orally in $10 \mathrm{ml}$ of $5 \%$ glucose. Urine was collected for 24 hours. Urine volumes were measured and two samples of $5 \mathrm{ml}$ each were counted in a well counter. A standard $1 / 100$ dilution of $5 \mathrm{ml}$ was similarly counted. Radioactivity excreted in the urine over a period of 24 hours was expressed as a percentage of the oral dose. In a previous paper, our control group of children showed a mean (2SD) ${ }^{51}$ Cr-EDTA excretion of $2 \cdot 5(1 \cdot 3) \% .{ }^{13}$ We therefore chose a cut off value of $3 \cdot 8 \%$ to evaluate the relationship 
Table 1 Clinical features of children with recurrent abdominal pain

\begin{tabular}{lll}
\hline & $\begin{array}{l}\text { Duodenal biopsy } \\
(n=39)\end{array}$ & $\begin{array}{l}\text { No duodenal biopsy } \\
(n=67)\end{array}$ \\
\hline Sex (male/female) & $15 / 24$ & $23 / 44^{*}$ \\
Mean age at entry (years) & $8 \cdot 25$ & $9 \cdot 23^{*}$ \\
Range & $5 \cdot 9-14$ & $5 \cdot 5-12 \cdot 4$ \\
Mean duration of complaints (months) & $26 \cdot 8$ & $19 \cdot 4^{*}$ \\
Range & $6-120$ & $6-80$ \\
Mean No of attacks/week & 4 & $3 \cdot 9^{*}$ \\
Range & Once a month-every day & Once a month-every day \\
Mean duration of attacks (hours) & $6 \cdot 3$ & $5 \cdot 3^{*}$ \\
Range & 5 min-all day & 5 min-all day \\
\hline
\end{tabular}

*No significant differences between groups (Wilcoxon test).

between small bowel permeability and duodenal inflammatory changes.

Clinical details regarding our patients are shown in table 1 . Of 106 patients with recurrent abdominal pain, 39 underwent endoscopy and biopsy of the duodenum. Duodenal biopsy specimens were taken after an overnight fast from the proximal duodenum with an Olympus GIF XP10 endoscope. All patients were sedated with midazolam (Dormicum) and atropine. One or two biopsy specimens from each patient were immediately placed in Bouin fixative. After embedding in paraffin they were cut into $4 \mu \mathrm{m}$ sections and stained with a haematoxylin and eosin. The most representative, well orientated sections were used for grading. Histological grading of duodenal inflammation was done according to the criteria laid down by Whitehead et al. ${ }^{14}$ The histological sections were examined by a pathologist who had no knowledge of the clinical or endoscopic findings. All sections were reviewed for this study by the same observer (JWA).

Although a certain bias may have been introduced in the group of patients $(n=39)$ who underwent duodenal biopsy ( $37 \%$ of the total study group), there appeared to be no significant differences between the two groups in clinical data (table 1) or ${ }^{51} \mathrm{Cr}$-EDTA excretion (table 2). There was, however, a tendency towards higher ${ }^{51} \mathrm{Cr}$-EDTA excretion values and a slightly longer duration of complaints in the group that underwent biopsy.

Only the results concerning intestinal per-

Table 2 Urinary ${ }^{51}$ Cr-EDTA excretion in different groups of patients

\begin{tabular}{|c|c|c|c|}
\hline & $\begin{array}{l}\text { All patients } \\
\text { with recurrent } \\
\text { abdominal pain } \\
(n=100)\end{array}$ & $\begin{array}{l}\text { Duodenal } \\
\text { biopsy } \\
(n=39)\end{array}$ & $\begin{array}{l}\text { No duodenal } \\
\text { biopsy } \\
(n=61)\end{array}$ \\
\hline $\begin{array}{l}{ }_{\text {S1Cr-EDTA excretion (\%) }} \\
\text { SEM } \\
\text { Range }\end{array}$ & $\begin{array}{l}3 \cdot 60^{*} \\
0 \cdot 16 \\
1 \cdot 1-10\end{array}$ & $\begin{array}{l}4 \cdot 11^{*} \\
0 \cdot 26 \\
1 \cdot 9-10\end{array}$ & $\begin{array}{l}\star 3 \cdot 24^{*} \\
0 \cdot 19 \\
1 \cdot 1-8\end{array}$ \\
\hline
\end{tabular}

*No significant differences between groups ( $t$ test)

Table 3 Results of the ${ }^{51} \mathrm{Cr}$-EDTA permeability test in 39 patients with recurrent abdominal pain with varying degrees of duodenal inflammation

\begin{tabular}{|c|c|c|c|c|c|}
\hline & \multicolumn{5}{|c|}{ Duodenitis } \\
\hline & $\begin{array}{l}0 \\
(n=11)\end{array}$ & $\begin{array}{l}l \\
(n=15)\end{array}$ & $\begin{array}{l}2 \\
(n=10)\end{array}$ & $\begin{array}{l}3 \\
(n=3)\end{array}$ & $\begin{array}{l}1,2 \text {, and } 3 \\
(n=28)\end{array}$ \\
\hline $\begin{array}{l}\text { 51 Cr-EDTA excretion (\%) } \\
\text { SEM } \\
\text { Range }\end{array}$ & $\begin{array}{l}3 \cdot 3 \\
0 \cdot 27 \\
1 \cdot 9-4 \cdot 7\end{array}$ & $\begin{array}{l}4 \cdot 64^{*} \\
0 \cdot 49 \\
2 \cdot 4-10\end{array}$ & $\begin{array}{l}4 \cdot 34 \\
0 \cdot 53 \\
2 \cdot 3-7 \cdot 5\end{array}$ & $\begin{array}{l}3 \cdot 67 \\
0 \cdot 59 \\
2 \cdot 3-4 \cdot 8\end{array}$ & $\begin{array}{l}4 \cdot 42^{* *} \\
0 \cdot 33 \\
2 \cdot 3-10\end{array}$ \\
\hline
\end{tabular}

Compared with grade $0:{ }^{*} \mathrm{p}<0.002,{ }^{* *} \mathrm{p}<0.05$ ( $t$ test)
Table 4 Relationship between ${ }^{51} \mathrm{Cr}-E D T A$ test results and duodenal inflammatory changes

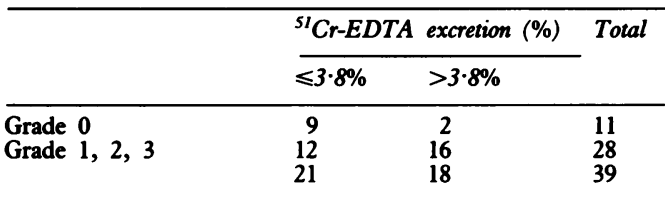

Relationship between abnormal small bowel permeability and duodenal inflammation: $p=0.03$ (Fisher's test, single tailed).

meability and duodenal biopsy results are reported in the present paper.

\section{Results}

Of the 39 patients who underwent duodenal biopsy, 13 (33\%) showed microscopically obvious signs of inflammation (10 and three with Whitehead grades 2 and 3, respectively), $15(38 \%)$ showed minimal changes (grade 1), whereas in 11 patients $(28 \%)$ the biopsy specimens looked normal (grade 0). A simultaneous antral biopsy was taken from 11 of these patients; in eight cases (73\%) Helicobacter pylori colonisation was detected on histological examination (three with grade 0 , one with grade 1 , 2 with grade 2 , and two with grade 3 duodenitis). Histological evidence of gastritis was present in four $(50 \%)$ of the patients in whom $H$ pylori was found. The combination of gastritis and duodenitis was present in three of the eight patients in whom $H$ pylori was found. Results of 24 hours ${ }^{51} \mathrm{Cr}$-EDTA excretion in all our 106 patients with recurrent abdominal pain are presented in table 2 . In six cases either the parents refused the test or urine sampling failed. The mean ${ }^{51} \mathrm{Cr}$-EDTA excretion values of patients with varying degrees of duodenal inflammation are shown in table 3 . The ${ }^{51} \mathrm{Cr}$ EDTA excretion of patients with grade 1 duodenal inflammation was significantly higher than that of patients with grade $0(p<0.02$, Student's $t$ test). Most notably, no differences were found between patients with grade 2 or grade 3 on the one hand, and grade 0 on the other. The mean ${ }^{51} \mathrm{Cr}$-EDTA excretion of patients with normal findings (grade 0), however, was significantly lower than that of patients with grades 1,2 , and 3 taken together ( $<<0.05$, Student's $t$ test).

Table 4 shows the relationship between normal and abnormal small bowel ${ }^{51} \mathrm{Cr}$-EDTA excretion values and the histological grading of the duodenal biopsy. It illustrates the significant relationship between abnormal small bowel permeability and inflammatory changes in the duodenum ( $p=0 \cdot 03$, Fisher's exact test).

\section{Discussion}

In a group of 66 children with recurrent abdominal pain, Ament and Christie found duodenitis in only two cases and duodenal ulcers in eight, but these diagnoses were made endoscopically and not confirmed histologically. ${ }^{15}$ In a group of 62 children with recurrent abdominal pain, Black et al described 
only nine cases with signs of histologically confirmed duodenitis. ${ }^{16}$ They used a histological grading system different from ours, however, which makes comparison between the studies difficult. In a retrospective study of $\mathbf{3 2 0}$ gastroduodenoscopies in children, Oderda et al reported only 32 cases with endoscopic signs of duodenal damage. ${ }^{17}$ Abdominal pain was the most common symptom in $\mathbf{2 5}$ of these patients (78\%), and the criteria of Whitehead et al for the histological diagnosis of duodenitis were met in only four. It is remarkable that three of these patients had recurrent abdominal pain. More recently, Glassman et al, using Whitehead's criteria, reported duodenitis in $47 \%$ of 95 children with epigastric pain. ${ }^{18}$

The criteria of Whitehead et al are generally accepted for classifying inflammatory lesions in the duodenum. Grade 0 describes a normal histological appearance. Grade 1 describes 'minimal change' duodenitis, and grades 2 and 3 are definitely abnormal, indicating the presence of duodenitis. ${ }^{14}$ The clinical relevance of the classification is, however, questionable, as minimal changes and even overt inflammation have been reported in healthy adult volunteers. ${ }^{19}$ Whether these observations are also applicable to children is brought into doubt by the data of Oderda et al. ${ }^{17}$ In the present study, a third of the patients with recurrent abdominal pain had definite signs of duodenitis: grades 2 and 3. Given the above reservations this supports our hypothesis that children with recurrent abdominal pain have a high incidence of intestinal inflammation.

Our results also show a significant relationship between intestinal permeability to ${ }^{51} \mathrm{Cr}$ EDTA and inflammatory changes. The minimal inflammatory changes described as grade 1 are often regarded as still within the reference range. In this context, it is remarkable that in our group of patients with grade 1 the ${ }^{51} \mathrm{Cr}$ EDTA excretion test yielded significantly higher results than in patients with normal findings (grade 0). Separately, however, patients with grades 2 or 3 duodenitis showed no significant differences from patients with grade 0 . This discrepancy may possibly be explained by the small numbers of patients in these two groups. This might shed new light on the relevance of grade 1 inflammatory changes and suggest that minimal inflammatory changes should be considered as abnormal being the precursor of full blown duodenitis. Alternatively it might represent an early healing stage before abnormal small bowel permeability had returned to normal. On the other hand, in those children in whom there was increased ${ }^{51} \mathrm{Cr}$-EDTA excretion together with a normal histological appearance of the duodenum, we are possibly dealing with false negative findings, as multiple biopsy specimens (which were not considered justifiable in this study), would be required to exclude the possibility of patchy lesions in the small bowel.

When (for the above mentioned reasons), all patients with inflammatory changes (Whitehead grades 1, 2, and 3) are taken together, there appears to be a significant relationship between abnormal ${ }^{51} \mathrm{Cr}$-EDTA excretion $(>3.8 \%)$ and the presence of inflammatory changes in the duodenum of patients with recurrent abdominal pain (table 3). On the basis of these numbers the ${ }^{51} \mathrm{Cr}$-EDTA test has a sensitivity of $57 \%$ and a specificity of $82 \%$ for the detection of duodenitis. Despite the apparently low sensitivity of the ${ }^{51} \mathrm{Cr}$-EDTA test, it still gives a positive predictive value of $89 \%$. Used in this way the ${ }^{31} \mathrm{Cr}$-EDTA may be a valuable diagnostic tool in children with recurrent abdominal pain, in screening for possible intestinal inflammatory changes. We certainly use it in clinical practice to find out if we are dealing with a possibly organic cause of the abdominal complaints; this we believe is justified by our findings in the present study.

The cause of the inflammatory changes in our patients still remains unclear. Recent studies (presented in a poster session at the first meeting of the European Campylobacter Study Group, Bordeaux, France, October 1988) by de Rafael et al and Mahony et al showed that Campylobacter pylori (now called Helicobacter pylori) was present in the antral mucosa of children with chronic gastritis and recurrent abdominal pain. $H$ pylori has, however, an affinity for gastric mucosa. ${ }^{20}$ Unfortunately, gastric biopsy specimens were not obtained from all patients in the present study. Glassman et al reported the presence of duodenitis without associated gastritis in $47 \%$ of patients from whom $H$ pylori was not isolated, whereas duodenitis associated with gastritis was found in $56 \%$ of their patients from whom $H$ pylori was isolated. ${ }^{18}$ In our patients with grades 2 or 3 duodenitis and $H$ pylori colonisation, three (37\%) showed associated microscopic gastritis. Furthermore, small bowel permeability to ${ }^{51} \mathrm{Cr}$ EDTA is abnormal in children with gastroenteritis, ${ }^{13}$ a condition that is associated with duodenal mucosal inflammation. ${ }^{21}$ Although we have only few data to support this contention, it seems likely that the inflammatory changes we found in our patients were in some cases caused by bacterial or viral infections.

Food hypersensitivity might also have a role in causing inflammation of the small bowel. Either a primary (food antigens) or a secondary (bacterial antigens) hypersensitivity reaction could result in a local intestinal inflammation whereby the intestinal wall could loose its ability to act as an effective barrier. The altered intestinal permeability would then allow the passage of more macromolecular antigens. This penetration of antigens could further aggravate the local hypersensitivity reaction, which would in the end result in widespread inflammatory changes and causes damage and disease. ${ }^{22} 23$ Some authors found a correlation between the irritable bowel syndrome and hypersensitivity to food. ${ }^{24-26}$ The symptomatology and pathophysiology in the irritable bowel syndrome seem closely related to recurrent abdominal pain in childhood. ${ }^{27}$ The findings in our patients and data from other authors seem to support the hypothesis that food hypersensitivity might play a part in recurrent abdominal pain.

Further studies are needed to elucidate the pathophysiological mechanisms in recurrent abdominal pain. It seems likely, however, that small bowel inflammation whether primary or 
secondary to different environmental factors, may play an important part in the pathogenesis of this frequently misunderstood problem in childhood.

We thank the Department of Child Health Maastricht (head: Dr FJM Feron) for cooperating in this study.

1 Apley J, Naish N. Recurrent abdominal pains: a field survey of 1000 school children. Arch Dis Child 1958;33:165-70.

2 Apley J. The child with abdominal pains. 2nd Ed. Oxford: Blackwell Scientific Publications, 1975.

3 Barr G, Levine DL, Watkins JB. Recurrent abdominal pain of childhood due to lactose intolerance. $N$ Engl f Med 1979;26:1449-52.

4 Pineiro-Carrero VM, Andres JM, Davis RH, Mathias JR. Abnormal gastroduodenal motility in children and adolescents with recurrent functional abdominal pain. $\mathcal{F}$ Pediatr 1988;5:820-5.

5 Schisgall RM. Radiographic features of appendiceal colic in children. Pediatr Radiol 1986;16:392-9.

6 Friedman R. Some characteristics of children with 'psychogenic' pain: observations on prognosis and treatment. Clin Pediatr (Phila) 1972:1:331-3.

7 Maddison TG. Recurrent abdominal pain in children. Med $\mathcal{F}$ Aust 1977;: 708-10.

8 McGrath PJ, Goodman JT, Firestone P, Shipman R, Peters S. Recurrent abdominal pain: a psychogenic disorder? Arch Dis Child 1983;58:888-90.

9 Raymer D, Weininger O, Hamilton JR. Psychological problems in children with abdominal pain. Lancet 1984;i: $439-40$

10 Van der Meer SB, Forget PP, Heidendal GAK. Small bowel permeability to ${ }^{51} \mathrm{Cr}$-EDTA in children with children with recurrent abdominal pain. Acta Paediatr Scand 1990;79. $422-6$

11 Bjarnason I, Peters TJ, Veall N. A persistent defect in intestinal permeability in celiac disease demonstrated by a ${ }^{51}$ Cr-labelled EDTA absorption test. Lancet 1983;i:323-5.

12 Biarnason I, O'Morian C, Levi AJ, Peters TJ. Absorption of matory bowel disease. Gastroenterology 1983;85:318-22.
13 Forget PP, Sodoyez-Goffaux F, Zapitelli A. Permeability of the small intestine to ${ }^{51} \mathrm{Cr}$-EDTA in children with acute gastroenteritis or eczema. $\mathcal{f}$ Pediatr Gastroenterol Nutr $1985 ; 4: 393-6$

14 Whitehead R, Roca, Meikle DD, Skinner J, Truelove SC The histological classification of duodenitis in fibreoptic biopsy specimens. Digestion 1975;13:129-36.

15 Ament ME, Christie DL. Upper gatrointestinal fiberoptic endoscopy in pediatric patients. Gastroenterology 1977,72: $1244-8$.

16 Black DD, Haggitt RC, Whitington PF. Gastroduodenal endoscopic-histologic correlation in pediatric patients. endoscopic-histologic correlation in pedia

17 Oderda G, Forni M, Farina L, Dell'Olio D, Ansaldi N. Duodenitis in children: clinical, endoscopic and pathoDuodenitis in children: clinical, endoscopic and

18 Glassman MS, Schwarz SM, Medow MS, et al. Campylobacte pylori-related gastrointestinal disease in children. Incidence and clinical findings. Dig Dis Sci 1989;34:1501-4.

19 Kreuning J, Bosman FT, Kuiper G, vd Wal AM, Lindeman . Gastric and duodenal mucosa in 'healthy' individuals. f Clin Pathol 1978;31:69-77.

20 Elta G, Kern S, Nostrant T, Appleman H. Campylobacter(ike orosive gastroduodenitis. Gastroenterolog 1987;92:1382.

21 Barnes GL, Townley RW. Duodenal mucosal damage in 31 infants with gastroenteritis. Arch Dis Child 1973;48:343-9.

22 Shorter RG, Huizenga KA, Spencer RJ. A working hypothesis for the etiology and pathogenesis of non-specific inflammatory bowel disease. American fournal of Digestive Diseases 1972;17:1024-32.

23 Ramage JK, Stanisz A, Scicchitano $R$, Hunt RH, Perdue MH. Effect of immunologic reactions on rat intestinal MH. Effect of immunologic reactions on rat

24 Petitpierre M, Gumowski P, Girard JP. Irritable bowel syndrome and hypersensitivity to food. Ann Allergy 1985; 54:538-40.

25 Alun Jones V, Shorthouse M, McLaughlan P, et al. Food intolerance: a major factor in the pathogenesis of irritable bowel syndrome. Lancet 1982;ii:1115-7.

26 Nanda R, James R, Smith H, Dudley CRK, Jewell DP. Food intolerance and the irritable bowel syndrome. Gut 1989;30: 1099-104.

27 Dotevall G, Svedlund J, Ssiodin I. Symptoms in irritable bowel syndrome. Scand $\mathcal{f}$ Gastroenterol 1982;79(suppl): $16-9$. 